\title{
Radiossensibilidade de sementes e segmentos caulinares de maracujazeiro-amarelo submetidos à radiação gama
}

\author{
The radio-sensitivity of gamma-irradiated passion \\ fruit seeds and stem nodal segments
}

\author{
Patrícia Silva Flores ${ }^{\mathrm{I}}$ Claudio Horst Bruckner ${ }^{\mathrm{II}}$
}

\section{RESUMO}

Os objetivos neste estudo foram avaliar os efeitos da radiação $\gamma$ sobre a sobrevivência e desenvolvimento de gemas de segmentos caulinares e germinação de sementes de maracujazeiroamarelo (Passiflora edulis f. flavicarpa) in vitro. Os explantes de segmentos caulinares $(2 \mathrm{~cm})$ contendo uma gema axilar, obtidos a partir de plântulas provenientes da germinação in vitro de sementes de maracujá, foram tratados com raios $\gamma$ em dosagens variando de 10 a 60 Gy e subsequentemente transferidos para meio Murashige e Skoog (MS), suplementado com 4,0mg $L^{-1}$ BAP. Para a irradiação das sementes, foram testadas doses que variaram de 75-200Gy e a germinação e sobrevivência das plântulas foram avaliadas após 30 e 60 dias da inoculação em meio MS, respectivamente. Após 30 dias da irradiação de segmentos caulinares, observou-se redução de 50\% na sobrevivência dos explantes e no número de brotações formadas in vitro nas doses de 21,31 e 12,20Gy, respectivamente. $A D L_{50}$ para a germinação de sementes é $160 G y$, enquanto que, para sobrevivência das plântulas, é de $125 \mathrm{~Gy}$.

Palavras-chave: raios gama, cultura de tecidos, germinação de sementes, P. edulis f. flavicarpa.

\section{ABSTRACT}

This study had the objective to investigate the effects of gamma ray radiation on survival and proliferation of shoots from stem nodal segments and on the germination seeds passion fruit (Passiflora edulis $\boldsymbol{f}$. flavicarpa). Stem segments explants $(2 \mathrm{~cm})$ containing one axillary bud obtained from in vitropropagated seedlings of passion fruit were treated with $\gamma$-rays at dosages ranging from 10 to $60 G y$ and subsequently transferred to Murashige and Skoog (MS) medium supplemented with $4.0 \mathrm{mg}$ $L^{-1} B A P$. Seeds of passion fruit were irradiated with gamma rays at dosages ranging from 75 to 200Gy. Germination and survival of seedlings were measured after 30 and 60 days of transfer to MS medium, respectively. After 30 days of irradiation of stem segments it was observed $50 \%$ reduction in survival of explants and the number of shoots formed in vitro at 21.31 and $12.20 \mathrm{~Gy}$ respectively. The $L D_{50}$ for seed germination is $160 G y$, while for seedling survival is $125 \mathrm{~Gy}$.

Key words: gamma ray, tissue culture, seed germination, $\boldsymbol{P}$. edulis f. flavicarpa.

\section{INTRODUÇÃO}

A adoção de tecnologias e o uso de mudas de qualidade contribuem para o sucesso da produção de maracujá-amarelo no Brasil, sendo responsável por $80 \%$ da produção mundial. No entanto, essa cultura tem como característica a necessidade de alteração de área para plantio, devido principalmente à susceptibilidade a doenças, em decorrência da falta de variedades resistentes (MELETTI, 2011).

Uma maneira de se obter variedades de plantas resistentes a patógenos é por meio da indução de mutações, que pode ser considerada como ferramenta para auxiliar no melhoramento genético de plantas (BHAGWAT \& DUNCAN, 1998; MADAMBA et al., 2009; SHARMA et al., 2010; SNYMAN et al., 2011). Através da técnica, cerca de 2250 variedades de plantas foram lançadas nas últimas décadas, incluindo importantes culturas, como arroz, trigo, algodão, canola, girassol, gergelim, toranja e banana, impactando significativamente a área cultivada e a economia mundial (AHLOOWALIA et al., 2004). Nesse sentido, a indução de mutações pode representar uma alternativa para obtenção de variantes

IEmbrapa Acre, 69900-970, Rio Branco, AC, Brasil. E-mail: patrícia.flores@embrapa.br. Autor para correspondência.

IIDepartamento de Fitotecnia, Universidade Federal de Viçosa (UFV), Viçosa, MG, Brasil. 
genéticas de maracujazeiro-amarelo para diferentes características, incluindo a resistência a doenças.

A mutação pode ser induzida por meio de mutagênicos físicos, como radiações ou químicos, os quais envolvem uma gama de produtos com diferentes modos de ação, sendo os raios gama $(\gamma)$ o agente mais utilizado na indução de mutações em plantas (AHLOOWALIA et al., 2004; PREDIERI, 2001). Os mutagênicos químicos, ao contrário dos físicos, podem ter baixa penetrabilidade nos tecidos e exigem maiores cuidados na manipulação durante e após os tratamentos (TULMANN NETO \& LATADO, 1999).

Apesar do custo de aquisição elevado dos irradiadores, o tratamento de materiais no país pode ser realizado sem custo algum, tanto para institutos oficiais como privados, no Centro de Energia Nuclear na Agricultura (CENA). Nesse local, foram obtidos avanços no melhoramento de importantes culturas, conforme revisado por TULMANN NETO et al. (2011).

$\mathrm{Na}$ indução de mutações, é necessário o tratamento de um grande número de propágulos para garantir o surgimento da variante genética com as características de interesse, de forma que a indução in vitro é vantajosa por possibilitar a aplicação dos agentes mutagênicos em um grande número de explantes em espaço reduzido. A cultura de tecidos também auxilia na obtenção de mutantes artificiais, por favorecer a maior uniformidade no tratamento, aumentar as chances de se obter mutantes sólidos a partir de gemas adventícias de origem unicelular ou por meio do isolamento dos setores mutantes, mediante sucessivas multiplicações (TULMANN NETO et al., 1998; PREDIERI, 2001). A técnica também possibilita a seleção da variante genética de interesse por meio da suplementação do meio de cultura com agentes seletivos (fitotoxinas, sais, dentre outros) sob elevada pressão de seleção no material tratado (MOHAN JAIN, 2002).

A seleção da dose de radiação para a mutação efetiva dos materiais tratados é requisito fundamental, sendo esta baseada em certo nível de letalidade produzido (Lethal Dose $50 \%$ ou $\mathrm{LD}_{50}$ ), na redução de características como altura da planta (Growth Reduction ou $\mathrm{GR}_{50}$ ), número de brotações produzidas, dentre outros (INTERNATIONALATOMIC ENERGY AGENCY, 2006). A avaliação apenas da sobrevivência pode não ser suficiente para determinação da dose, pois as plantas sobreviventes podem ter problemas no crescimento e desenvolvimento, sendo, nesse caso, necessária a adoção de outra característica (TULMANN NETO et al., 1998).

As doses de radiação gama utilizadas para indução de mutações em tecidos somáticos de várias espécies de plantas são menores que aquelas utilizadas em sementes (5 a 100Gy e 60 a 700Gy, respectivamente) (AHLOOWALIA \& MALUSZINSKY, 2001). Em segmentos foliares de P. edulis f. flavicarpa, OTAHOLA (1999) observou a $\mathrm{DL}_{50}$ entre 15 e 20Gy, enquanto CALDERÓN (2011) relatou que a dose para reduzir em $50 \%$ a formação de brotações por explante de segmentos nodais de $\boldsymbol{P}$. edulis f. edulis situou-se por volta de 50Gy.

Em sementes de $\boldsymbol{P}$. edulis $\boldsymbol{f}$. flavicarpa, TORNE \& DESAI (1975) obtiveram a LD $_{50}$ entre 100 e $125 \mathrm{~Gy}$, enquanto SENANAYAKE \& PERERA (1977) e OTAHOLA (1999) observaram a tolerância maior das sementes da espécie à radiação, ficando a $\mathrm{LD}_{50}$ em 200 e $150 \mathrm{~Gy}$, respectivamente. Esses dados evidenciam que, para o mesmo tipo de tecido, a dose ideal de radiação $\gamma$ varia conforme o estado fisiológico e teor de água, os quais não são informados pela maioria dos autores.

Neste estudo, os objetivos foram avaliar os efeitos da radiação $\gamma$ sobre a sobrevivência e desenvolvimento de segmentos caulinares e germinação de sementes de maracujazeiro-amarelo in vitro.

\section{MATERIAL E MÉTODOS}

Neste trabalho, os explantes de segmentos caulinares e sementes de maracujazeiro-amarelo foram tratados com doses de raios $\gamma$ produzidos por fonte de ${ }^{60} \mathrm{Co}$. As fontes são provenientes de irradiador do tipo Gamma Cell do Centro de Energia Nuclear na Agricultura (CENA) da Universidade de São Paulo, localizado em Piracicaba, São Paulo. O material vegetal utilizado foi obtido de plantios de maracujazeiro localizados na área experimental do setor de fruticultura, no campus da Universidade Federal de Viçosa (UFV), em Viçosa, Minas Gerais.

Para a obtenção dos explantes de segmentos caulinares, plântulas provenientes da germinação de sementes de maracujazeiro em meio MURASHIGE \& SKOOG (1962) (MS) foram segmentadas em porções de $2 \mathrm{~cm}$ de caule, contendo uma gema axilar. Os explantes foram transferidos para placas de Petri contendo $30 \mathrm{~mL}$ de meio MS com metade da concentração dos sais, sendo depositados 10 explantes por placa e, para cada dose de radiação testada, foram irradiadas quatro placas, totalizando 40 explantes por tratamento.

Os segmentos caulinares foram inicialmente irradiados a 15, 30, 45 e $60 \mathrm{~Gy}$ e, em um experimento posterior, novos explantes de segmentos caulinares foram irradiados a 10, 15, 20 e 25Gy para maior aproximação da $\mathrm{DL}_{50}$. Após as irradiações, os 
explantes foram transferidos para tubos de ensaio contendo $10 \mathrm{~mL}$ de meio de cultura MS suplementado com $1 \mathrm{mg} \mathrm{L}^{-1}$ de BAP. O material foi incubado por 30 dias em sala de crescimento com fotoperíodo de 16 horas e densidade de fluxo luminoso de $32 \mu \mathrm{mol} \mathrm{m} \mathrm{m}^{-2} \mathrm{~s}^{-1}$, à temperatura de $27 \pm 2^{\circ} \mathrm{C}$ no Laboratório de Cultura de Células e Tecidos Vegetais do Departamento de Fitotecnia da UFV. Após este período, foram avaliadas a porcentagem de sobrevivência do explante e número de brotações formadas.

Para as avaliações dos efeitos de doses de raios $\gamma$ em sementes de maracujazeiro-amarelo, foram utilizadas sementes coletadas de frutos maduros com cerca de $10 \%$ de umidade no momento da semeadura, determinado conforme metodologia descrita nas Regras para Análise de Sementes (BRASIL, 2009). Os frutos foram seccionados transversalmente para extração das sementes e, em seguida, houve a retirada da mucilagem por meio de fricção com cal virgem em peneira de malha fina. As sementes foram lavadas em água corrente e dispostas em papel toalha, onde foram mantidas durante três dias para secagem à sombra. Para a irradiação com as doses de raios gama $75,100,125,150,175$ e $200 \mathrm{~Gy}$, foram utilizadas cinco repetições com 100 sementes, totalizando 500 sementes para cada dose.

Em câmara de fluxo laminar, as sementes irradiadas foram imersas em etanol 70\% durante um minuto e, após, em solução de hipoclorito ( $2 \%$ de cloro ativo) durante 20 minutos; em seguida, enxaguadas com água destilada e esterilizadas em autoclave por três vezes. Com auxílio de bisturi, as sementes foram escarificadas, com uma incisão na região distal da semente e transferidas para tubos de ensaio contendo $10 \mathrm{~mL}$ do meio de cultura MS, contendo metade da concentração dos sais. Após 30 dias, foi avaliada a porcentagem de germinação de sementes que formaram plântulas normais e, aos 60 dias da germinação, avaliou-se a sobrevivência das plântulas.

Para as irradiações dos segmentos caulinares e de sementes, as taxas de dose do irradiador variaram de 0,709 a $0,711 \mathrm{kGy} \mathrm{h}^{-1}$. Para a determinação da dose de radiação necessária para a redução de 50\% das características avaliadas (número de brotações, sobrevivência dos explantes, germinação de sementes e sobrevivência das plântulas), os valores obtidos com os tratamentos foram comparados com os valores observados nas testemunhas, compostas de segmentos caulinares e sementes não irradiadas.

Para a irradiação dos segmentos caulinares, foram utilizados oito tratamentos $(0,10,15,2025,30$, 45 e $60 \mathrm{~Gy})$ e, para cada tratamento, foram utilizadas quatro repetições, sendo cada parcela constituída de 10 tubos de ensaio contendo as culturas. Para o estudo do efeito da irradiação sobre as sementes, foram testados sete tratamentos $(0,75,100,125$, 150, 175 e 200Gy), cada um composto de cinco repetições, correspondentes a 50 tubos, sendo que cada um continha duas sementes em meio de cultura. $\mathrm{O}$ delineamento experimental utilizado em ambos os experimentos foi completamente casualizado, os dados foram submetidos à análise da regressão e as avaliações estatísticas foram realizadas com o auxílio do programa estatístico SAEG 9.1.

\section{RESULTADOS E DISCUSSÃO}

As doses de radiações entre 15 a 60Gy afetaram significativamente a sobrevivência e a produção de brotações sobre os explantes de segmentos caulinares de maracujazeiro-amarelo. De acordo com a equação resultante, as doses de radiação estimadas para reduzir o número de brotações e porcentagem de sobrevivência em 50\% foram de 12,20 e de 21,31Gy, respectivamente (Figura 1A).

No segundo ensaio, em que foram testadas doses de 10 a 25Gy, foi observado que a dose letal média para a produção de brotações e a $\mathrm{LD}_{50}$ (sobrevivência) ficaram próximas de 20Gy, sendo os valores exatos estimados em 18,32 e 21,64Gy, respectivamente (Figura 1B). Essas observações foram consistentes com OTAHOLA (1999), quando comentou que a $\mathrm{LD}_{50}$ para a porcentagem de explantes de segmentos foliares de maracujazeiroamarelo com brotações foi observada próxima de 20Gy. Apesar de o autor ter utilizado tecido de origem diferente (segmentos foliares) ao do presente trabalho (segmentos caulinares), observou-se semelhança na tolerância à irradiação com raios $\gamma$, o que pode indicar a aproximação da dose padrão para irradiação in vitro de tecidos somáticos de $\boldsymbol{P}$. edulis $\boldsymbol{f}$. flavicarpa.

O tratamento com a dose de 10 Gy resultou no estímulo da produção de brotações, porque, com esta dose, foram produzidas 7,6 brotações por explante, enquanto que, nos segmentos caulinares não irradiados, a produção foi de 6,6 (Figura 1B).Utilizando essa mesma dose de raios $\gamma$ (10Gy), KIDO (2003) observou o estímulo na formação de brotações em explantes de gemas axilares de bananeira. $\mathrm{O}$ aumento no número de brotações em explantes tratados com baixas doses de agentes mutagênicos também foi observado por BHAGWAT \& DUNCAN (1998) e SRIVASTAVA et al. (2011) em bananeira e trigo, respectivamente.

O estímulo ao crescimento vegetal com o uso de baixas doses de raios gama pode ocorrer devido 


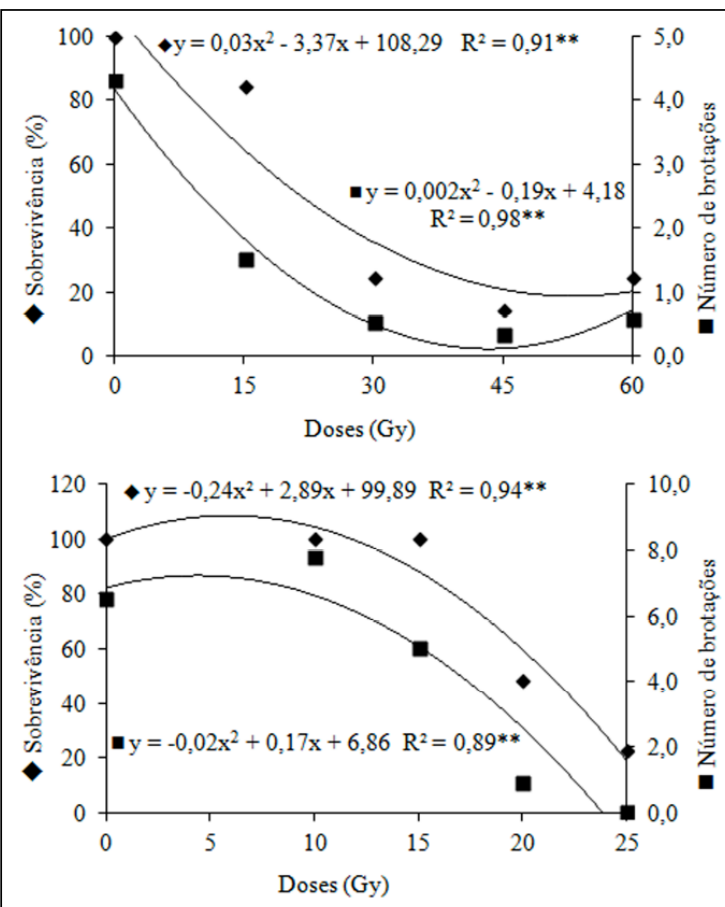

Figura 1 - Efeito da radiação gama sobre a sobrevivência e número de brotações em explantes de segmentos caulinares de $\boldsymbol{P}$. edulis $\boldsymbol{f}$. flavicarpa, após 30 dias da inoculação em meio MS com $1 \mathrm{mg} \mathrm{L}^{-1} \mathrm{BAP}$; A- Primeiro ciclo de seleção a 15, 30, 45 e 60Gy; B - Segundo ciclo de seleção a $10,15,20$ e $25 \mathrm{~Gy}$. **significativo $(\mathrm{P}<0,01)$.

a mudanças na sinalização hormonal nas células vegetais ou pelo aumento da capacidade antioxidativa das células, fazendo com que estas adquiram uma maior capacidade em superar fatores de estresse do ambiente (WI et al,. 2007). A partir da dose de 30Gy, houve o decréscimo nas características avaliadas, uma vez que, com o aumento da dose do tratamento mutagênico, normalmente se observa a redução na sobrevivência e na capacidade de regeneração das brotações.

Para as sementes submetidas à irradiação $\gamma$, quando comparadas a dos explantes de segmentos caulinares, observou-se maior tolerância daquelas (Figura 1), confirmando observações de AHLOOWALIA \& MALUSZINSKY (2001) e OTAHOLA (1999). A sensibilidade aos mutagênicos físicos varia conforme o grau de diferenciação dos tecidos, a fase do ciclo celular e o teor de água na célula, visto que a molécula de água é o mais frequente alvo primário da radiação ionizante (PIRI et al., 2011). As gemas caulinares são compostas de tecidos altamente meristemáticos e com teor de água geralmente maior que sementes. Esses fatores podem ter contribuído para a diferença observada na tolerância destes materiais à radiação.
De acordo com os resultados, a $\mathrm{LD}_{50}$ para germinação de sementes foi de 160Gy (Figura 2), semelhante ao observado por TORNE \& DESAI (1975) e OTAHOLA (1999), que obtiveram a LD $_{50}$ para germinação de sementes de maracujazeiroamarelo por volta de 100 a 150Gy. Porém, SENANAYAKE \& PERERA (1977) observaram a maior tolerância das sementes de maracujazeiro à radiação gama, ficando a $\mathrm{LD}_{50}$ entre as doses de 175 (64\%) e 200Gy (32\%), provavelmente, devido a diferenças na idade das sementes e ao teor de água que, conforme mencionado anteriormente, constitui-se em um dos fatores a influenciar na tolerância à radiação. Essa grande variação na dose de radiação necessária para a redução em $50 \%$ da germinação de sementes de maracujazeiro-amarelo, observada na literatura, reforça a importância de se caracterizar corretamente o material a ser irradiado, principalmente com relação ao grau de umidade, para que os resultados possam ser reproduzidos durante a aplicação prática da metodologia de indução de mutações.

Após 30 dias da germinação das sementes, foi observada sobrevivência de $50 \%$ das plântulas obtidas das sementes tratadas com 125Gy (Figura 2) e, apesar de a maioria dos autores determinarem a $\mathrm{LD}_{50}$ para germinação como característica para a indução de mutações em sementes, a mortalidade das plântulas obtidas pode limitar avaliações posteriores, devido ao número reduzido de material. De maneira semelhante, SENANAYAKE \& PERERA (1977) obtiveram 20\% de germinação de sementes de maracujazeiro-amarelo tratadas com 250Gy, no entanto, após três semanas, nenhuma plântula tratada com esta dose sobreviveu, reforçando a importância de se considerar diferentes variáveis para a escolha da dose do agente mutagênico. Essas observações podem estar relacionadas ao fato de que a absorção de água pelo embrião, etapa inicial da germinação, não é afetada pela mutagênese, sendo seu

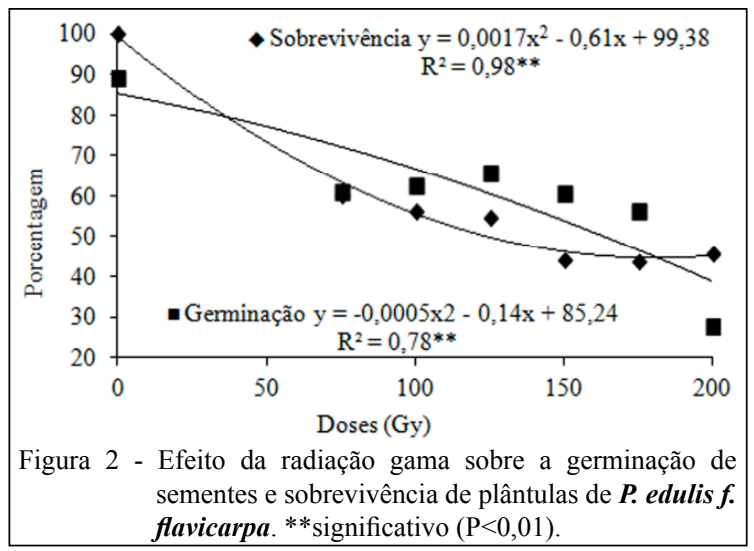

Ciência Rural, v.45, n.12, dez, 2015. 
efeito mais pronunciado sobre o desenvolvimento das estruturas primárias da plântula (INTERNATIONAL ATOMIC ENERGY AGENCY, 2006), as quais garantirão sua sobrevivência.

\section{CONCLUSÃO}

A irradiação de segmentos caulinares de maracujazeiro-amarelo nas doses de 21,31 e 12,20Gy reduz em $50 \%$ o número de brotações formadas in vitro e sobrevivência dos explantes, respectivamente. $\mathrm{A} \mathrm{DL}_{50}$, para a germinação de sementes, é de $160 \mathrm{~Gy}$ e, para sobrevivência das plântulas, é de 125Gy.

\section{AGRADECIMENTOS}

Os autores agradecemà Coordenação deAperfeiçoamento de Pessoal de Nível Superior (CAPES) e ao Conselho Nacional de Desenvolvimento Científico e Tecnológico (CNPq), pelo auxílio financeiro, e ao Dr. Tulmann, por possibilitar a irradiação do material no Centro de Energia Nuclear na Agricultura (CENA).

\section{REFERÊNCIAS}

AHLOOWALIA, B.S.; MALUSZINSKY, M. Induced mutations: a new paradigm in plant breeding. Euphytica, v.119, n.2, p.67-173, 2001. Disponível em: <http://link.springer.com/ article/10.1023/A:1004162323428>. Acesso em: 25 nov. 2012. doi: $10.1023 / \mathrm{A}: 1004162323428$.

AHLOOWALIA, B.S. et al. Global impact of mutation-derived varieties. Euphytica, v.135, n.2, p.187-204, 2004. Disponível em: <http://link. springer.com/article/10.1023/B:EUPH.0000014914.85465.4f $>$. Acesso em: 25 nov. 2012. doi: 10.1023/B:EUPH.0000014914.85465.4f.

BHAGWAT, B.; DUNCAN, E.J. Mutation breeding of Highgate (Musa acuminata, AAA) for tolerance to Fusarium oxysporum f. sp. cubense using gamma irradiation. Euphytica, v.101, n.2, p.143-150, 1998. Disponível em: <http://link.springer.com/ article/10.1023\%2FA\%3A1018391619986.>. Acesso em: 25 nov. 2012. doi: 10.1023/A:1018391619986.

BRASIL. Ministério da Agricultura, Pecuária e Abastecimento. Regras para análise de sementes. Secretaria de Defesa Agropecuária. Brasília: MAPA/ACS, 2009. 395p.

CALDERÓN, L.A.P. Inducción de mutaciones mediante radiaciones gamma de (Passiflora edulis Sim var. edulis). 2011. 105f. Dissertação (Maestría en Biología - Línea Genética) Facultad de Ciencias, Universidad Nacional de Colombia.

INTERNATIONAL ATOMIC ENERGY AGENCY. Plant breeding unit/activities report, 2006. Disponível em: $<\mathrm{http} / /$ www-naweb.iaea.org/nafa/pbg/public/plant_final_web06.pdf $>$. Acesso em: 05 nov. 2012.

KIDO, L.M.H. Irradiação de gemas axilares, suspensão celular e protoplastos de bananeira cv. Maçã (Musa spp.), visando a seleção de mutantes resistentes à salinidade. 2003. 136f. Tese (Doutorado em Ciência - Energia Nuclear na Agricultura) - Centro de Energia Nuclear na Agricultura, Universidade de São Paulo, SP.
MADAMBA, M.R.S. et al. A recessive mutation in rice conferring non-race-specific resistance to bacterial blight and blast. Rice, v.2, n.2-3, p.104-114, 2009. Disponível em: <http://link.springer.com/ article/10.1007/s12284-009-9027-x>. Acesso em: 25 nov. 2012. doi: $10.1007 / \mathrm{s} 12284-009-9027-\mathrm{x}$.

MELETTI, L.M.M. Avanços na cultura do maracujá no Brasil. Revista Brasileira de Fruticultura, v.33, n. esp, p.83-091, 2011. Disponível em: <http://dx.doi.org/10.1590/S010029452011000500012.>. Acesso em: 25 nov. 2012. doi: 10.1590/ S0100-29452011000500012.

MOHAN JAIN, S. A review of induction of mutation in fruit of tropical and subtropical regions. Acta Horticulturae, v.575, n.1, p.295-302, 2002. Disponível em: <http://www.actahort.org/ books/575/575 33.htm>. Acesso em: 25 nov. 2012.

MURASHIGE, T.; SKOOG, F. A revised medium for a rapid growth and bioassays with tobacco tissues cultures. Plant Physiology, v.15, n.3, p.473-479, 1962. Disponível em: <http:// onlinelibrary.wiley.com/doi/10.1111/j.1399-3054.1962.tb08052.x/ abstract>. Acesso em: 25 nov. 2012. doi: 10.1111/j.13993054.1962.tb08052.x

OTAHOLA, G.V.A. Radiosensibilidad de las semillas y diferentes tipos de explantes en cultivo in vitro de parchita (Passiflora edulis f. flavicarpa Deg.) a radiaciones gamma. 1999. 155f. Dissertação (Magíster Scientiarum en Agricultura Tropical) - PostGrado-Agricultura Tropical, Universidad de Oriente Venezuela.

PIRI, I. et al. The use of gamma irradiation in agriculture. African Journal of Microbiology Research, v.5, n.32, p.5806-5811, 2011. Disponível em: <http://www.academicjournals.org/article/ article1380793728_Piri\%20et\%20\%20al.pdf>. Acesso em: 25 nov. 2012. doi: 10.5897/AJMR11.949.

PREDIERI, S. Mutation induction and tissue culture in improving fruits. Plant Cell, Tissue and Organ Culture, v.64, n.2-3, p.185-210, 2001. Disponível em: <http://link.springer.com/ article/10.1023/A:1010623203554>. Acesso em: 25 nov. 2012. doi: 10.1023/A:1010623203554.

SENANAYAKE, Y.; PERERA, L. Radiosensitivity of winged bean and passion fruit seeds on gamma irradiation. Journal National Science Council Sri Lanka. v.5, n.2, p.125-132, 1977.

SHARMA, A. et al. Induction of Fusarium wilt (Fusarium oxysporum f. sp. pisi) resistance in garden pea using induced mutagenesis and in vitro selection techniques. Euphytica, v.173, n.3, p.345-356, 2010. Disponível em: <http://link.springer.com/ article/10.1007/s10681-009-0099-x>. Acesso em: 25 nov. 2012. doi: 10.1007/s10681-009-0099-x.

SNYMAN, S.J. et al. Applications of in vitro culture systems for commercial sugarcane production and improvement. In Vitro Cellular and \& Developmental Biology Plant, v.47, n.2, p.234-249, 2011. Disponível em: <http://link.springer.com/ article/10.1007/s11627-011-9354-7>. Acesso em: 25 nov. 2012. doi: 10.1007/s11627-011-9354-7.

SRIVASTAVA, P. et al. Mutagenic effects of sodium azide on the growth and yield characteristics in wheat (Triticum aestivum L. em. Thell.). Asian Journal of Plant Sciences, v.10, n.3, p.190- 
201, 2011. Disponível em: <http://docsdrive.com/pdfs/ansinet/ ajps/2011/190-201.pdf>. Acesso em: 25 nov. 2012. doi: 10.3923/ ajps.2011.190.201.

TORNE, S.G.; DESAI, N.P.R. Effect of ionizing radiation on seed germination of Passiflora species. Current Science, v.44, n.4, p.112-113, 1975 .

TULMANN NETO, A.; LATADO, R.R. Indução e seleção de mutações para o melhoramento de ornamentais e as perspectivas de sua utilização no Brasil. Revista Brasileira de Horticultura Ornamental, v.1, n.15, p.1-11, 1999.

TULMANN NETO, A. et al. Progressos na indução e uso de mutações in vitro. In: TORRES, A.C. et al. Cultura de tecidos e transformação genética de plantas. Brasília: Embrapa-CBAB, 1998. V.1, p.459-508.

TULMANN NETO, A. et al. Genetic improvement of crops by mutation techniques in Brazil. Plant Mutation Reports, v.2, n.3, p.24-37, 2011. Disponível em: <http://www-naweb.iaea.org/nafa/ pbg/public/pmr-02-03.pdf>. Acesso em: 25 nov. 2012. ISSN 1011-2650.

WI, S.G. et al. Effects of gamma irradiation on morphological changes and biological responses in plants. Micron, v.38, n.6, p.553-564, 2007. Disponível em: <http://www.sciencedirect.com/ science/article/pii/S0968432806002058>. Acesso em: 25 nov. 2013. doi: 10.1016/j.micron.2006.11.002. 